\title{
Uber, el cisne negro de los taxis
}

\author{
Pablo Sánchez Nássif / Luis Ricardo Morello Bustios \\ / Bardo Untiveros Riveros
}

Estudio Ghersi Abogados, Lima, Perú

Recibido: 5/8/2018 / Aprobado: 9/1/2019

doi: 10.26439/iusetpraxis2018.n48-49.4503

\begin{abstract}
Resumen. Uber, Easy Taxi, Taxi Beat y los demás servicios de taxi a través de plataformas de interconexión entre taxistas (o conductores privados, como estas los llaman) y pasajeros han demostrado ser beneficiosas no solo para los usuarios, sino también, como una verdadera mano invisible, para los terceros ajenos a cada transacción: gracias a estos aplicativos hay menos tráfico, menos taxistas deambulando por las calles. Sin embargo, en la práctica, estas plataformas incurren en actos de competencia desleal por violación de normas, pues la ordenanza municipal que regula el servicio de taxi en Lima Metropolitana no permite innovaciones en el servicio. ¿La solución es eliminar los servicios de plataforma? No. La solución, en realidad, es modificar las reglas.
\end{abstract}

\section{PALABRAS CLAVE: taxi / beneficio / usuario / competencia desleal / norma / ordenanza municipal}

\section{Uber, the black swan of taxis}

Aвstract. Uber, Easy Taxi, Taxi Beat and the other taxi services offered via platforms for interconnection between taxi drivers (or private drivers according to these apps) and passengers have shown to be beneficial not only for their users but also as a true invisible hand for third parties unrelated to each transaction. Thanks to these applications, there is less traffic jam and fewer taxi drivers wandering the streets. However, in practice, these platforms get involved in unfair competition for breach of regulations, because the city ordinance regulating the taxi service in Lima Metropolitan Area does not allow innovations in the service. Is the solution to eliminate platform services? No. The solution is actually to modify the rules.

KEYWORDS: taxi / benefit / user / unfair competition / standard / municipal ordinance 
De la observación de un sinnúmero de cisnes blancos no se podrá inferir que todos los cisnes son blancos; sin embargo, ver un solo cisne negro será suficiente para refutar semejante conclusión.

David Hume

\section{SOBRE LA INFINITA BÚSQUEDA DE REgLAS}

Día tras día se conocen sucesos que quedan completamente fuera de lo previsto, pero las personas no pueden imaginar que no los hubieran previsto. Gran parte de lo que ocurre se habría considerado una auténtica locura en el pasado. Pero luego no parece tan disparatado una vez que pasa. Esta verosimilitud retrospectiva produce una disminución de la rareza y el carácter concebible del suceso (Taleb, 2008).

Por ejemplo: ¿por qué se necesita autorización previa para colocar un anuncio en una fachada? Dado que en ocasiones pasadas un anuncio cayó de una fachada y dañó a los transeúntes, el Estado (conformado por seres humanos, con emociones), basándose en esos hechos pasados, no puede evitar considerar que el daño se produjo por negligencia del que colocó el anuncio. Resultado: normas que regulan la colocación de anuncios.

Así, pasamos de una sociedad sin regulación a una cada vez más regulada. En la medida en que la iniciativa privada descubre alternativas a las reglas, el legislador corre y crea una nueva. Al parecer, todos, incluyendo el Estado, no soportamos la idea de que exista algo fuera de lo previsto (y si ocurre, moldeamos nuestras ideas de tal manera que abarquen a este hecho nuevo). Necesitamos que las cosas tengan sentido $\mathrm{y}$, con esta lógica, nada tiene más sentido que una regla.

En el caso del servicio de taxi brindado a través de las plataformas de interconexión, exactamente ocurre esta situación:

1. Idea previa: tenemos una norma que regula el servicio de taxi.

2. Hecho nuevo: sistema de interconexión en línea entre taxistas y pasajeros.

3. Consecuencia: todo funciona a la perfección, hasta que se inician los problemas (robos, cobros indebidos, acoso, etcétera). 
4. Idea nueva: ampliar la regulación, de tal manera que se cubra y limite al nuevo sistema de interconexión.

No importa que el hecho nuevo sea totalmente ajeno a las causas que dieron origen a la idea previa (¿acaso la regulación evitará los robos o el acoso?). Lo cierto es que nos hemos acostumbrado a que ante toda innovación se deban buscar las reglas. Así, pasamos de una regla básica a una regla cada vez más amplia (lo que explica el porqué del exceso normativo en nuestro país). Una vez que todo funciona bajo las reglas, cobra sentido. Solo así nos sentimos satisfechos.

En filosofía, los servicios de taxi a través de plataformas de interconexión entre taxistas y pasajeros serían un cisne negro digno de Hume: una idea disruptiva en el mercado de taxis que nadie conoce y que, por tanto, plantea la duda de si en realidad es un servicio de taxi o no. No porque todos los taxis que conozcamos sean amarillos, significa que todos los taxis, necesariamente, deban ser amarillos. Puede haber taxis de otro color que sencillamente no conocemos. Así ocurre con estos aplicativos: quizá estemos ante un nuevo tipo de servicio de taxi.

\section{SEgúN NUESTRO SISTEMA NORMATIVO, UbER Y SERVICIOS SIMILARES INCURREN EN ACTOS DE COMPETENCIA DESLEAL}

Desde hace ya unos años, el servicio de taxi brindado por empresas a través de plataformas de interconexión, como Uber, ha ganado terreno en nuestro mercado. El antiguo sistema de taxis, que aún opera, supone, entre otras cosas:

- La existencia de conductores que dan vueltas por la ciudad a la espera de que algún pasajero los tome.

- La necesidad de los pasajeros de trasladarse a alguna avenida a esperar la llegada de algún taxi.

- La negociación de una tarifa.

Esa forma de operar del mercado de taxis está siendo superada por el nuevo sistema que proponen las empresas que brindan servicio de taxi a través de plataformas de interconexión, que requiere menos recursos y genera muchos beneficios:

- Los conductores no necesitan dar vueltas por la ciudad para contactar pasajeros, por lo que ahorran combustible y evitan generar más tráfico en la ciudad. 
- Los pasajeros ya no deben caminar por las calles en búsqueda de los conductores, y esperar a que alguno aparezca. Ahora los taxistas acuden, en pocos minutos, al punto exacto donde es requerido el servicio.

- La tarifa se encuentra previamente negociada. El taxista que accede al sistema, al igual que el usuario, ha aceptado la imposición de la tarifa por parte de la empresa en función del tiempo y del kilometraje recorrido en cada traslado.

Los taxistas hoy pueden valerse de la tecnología para realizar más carreras de una forma más eficiente. Por lo tanto, los pasajeros obtienen los servicios en mejores condiciones y más baratos.

No obstante, a pesar de todos los beneficios que estas aplicaciones suponen, en muchos países se ha sancionado o denunciado a Uber por diversos actos: competencia desleal ${ }^{1}$, incumplimiento de normas sobre transporte ${ }^{2}$, abusos laborales ${ }^{3}$ e incluso engaño ${ }^{4}$. Es curioso: los individuos ven a Uber como una oportunidad, pero los Estados (que a fin de cuentas son los representantes de los individuos) lo tratan como una amenaza.

En realidad, hay muchísimas maneras de sancionar a Uber. Todo depende de cuán restrictivas sean las normas y de qué tan creativo haya sido el legislador de turno. Particularmente, en nuestra Ley de Represión de Competencia Desleal (Decreto Legislativo 1044, 2008), se consideran ilícitos los actos de violación de normas.

Artículo 14.- Actos de violación de normas

14.1. Consisten en la realización de actos que tengan como efecto real o potencial valerse en el mercado de una ventaja significativa derivada de la concurrencia en el mercado mediante la infracción de normas imperativas.

1 En abril del 2017, el Tribunal Civil de Italia ordenó el bloqueo de la aplicación de Uber, debido a competencia desleal ("Uber es prohibido en Italia por competencia desleal", 2017).

2 En diciembre del 2016, la Superintendencia de Puertos y Transporte de Colombia sancionó millonariamente a Uber por "prestar servicios de transporte ilegalmente". También en Taiwán se sancionó a Uber: en febrero del 2017, el Ministerio de Transporte de Taiwán ordenó a Uber que cese sus operaciones hasta que respete las normas sobre el transporte.

3 En Inglaterra, una corte declaró que los conductores no eran "autoempleados", sino trabajadores de Uber, y que había que reconocerles derechos laborales.

4 A inicios del 2017, Uber tuvo que negociar con la Comisión Federal de Comercio de Estados Unidos un pago de 20 millones de dólares para evitar una multa por un monto mucho mayor. 
A fin de determinar la existencia de una ventaja significativa, se evaluará la mejor posición competitiva obtenida mediante la infracción de normas.

La lógica de la norma es la siguiente: una empresa que no cumple con las normas regulatorias ahorra los costos derivados del cumplimiento. En consecuencia, obtiene una ventaja competitiva frente a los demás competidores, quienes sí cumplen con la norma y, por tanto, asumen dichos costos. Tal aprovechamiento resulta "injusto" $y$, en consecuencia, el Instituto Nacional de Defensa de la Competencia y de la Protección de la Propiedad Intelectual (Indecopi) debe sancionarlo.

Esto ocurre con las aplicaciones de taxis. De acuerdo con la Ordenanza Municipal 1684 (2013), que regula la prestación del servicio de taxi en Lima Metropolitana, este se define de la siguiente manera:

Es el servicio de transporte público especial de personas de ámbito provincial prestado en vehículos de la categoría vehicular M1, conforme con la clasificación establecida en el RNV, que tiene por objeto la movilización de personas desde un punto de origen hasta uno de destino señalado por quien lo contrata, de forma individual y por la capacidad total del vehículo. El servicio de taxi se caracteriza por su no sujeción a rutas, itinerarios y horarios.

Teniendo en cuenta esta definición, Uber y los demás aplicativos ¿brindan o no un servicio de taxi? Si lo hacen, estarían sujetos a las regulaciones que contiene dicha ordenanza municipal: características de los vehículos, obligaciones, registros, sanciones, etcétera.

Uber ha sostenido, en los procedimientos por infracción a las normas de protección al consumidor seguidos ante Indecopi, que no brindan un servicio de transporte, sino que se limitan a contactar y organizar a usuarios conductores con usuarios pasajeros. Así, Uber solo sería un tercero ajeno al servicio de transporte, tal como aduce en el numeral 2 de sus "Términos y condiciones":

Los Servicios constituyen una plataforma de tecnología que permite a los usuarios de aplicaciones móviles de Uber o páginas web proporcionadas como parte de los Servicios (cada una, una "Aplicación") organizar y planear el transporte y/o servicios de logística con terceros proveedores independientes [las cursivas son nuestras] de dichos servicios, incluidos terceros transportistas independientes y terceros proveedores logísticos independientes, conforme a un acuerdo con Uber o algunos afiliados de Uber. (Uber B. V., 2017) 
Como veremos a continuación, la defensa de Uber se ha limitado siempre a sostener que en sus términos y condiciones señalan claramente que no brindan un servicio de transporte. Sin embargo, en la práctica, ¿es así?

\section{¿Qué servicio brinda Uber?}

Uber sostiene que ellos no prestan ningún servicio de transporte, ya que este sería brindado directamente por el chofer de la unidad al usuario, y no por ellos. Sin embargo, se puede decir que Uber sí proporciona el servicio de taxi, ya que es con esta empresa con la que el usuario contrata el servicio de transporte, es Uber quien designa al taxista que recogerá al pasajero, y es Uber quien fija las condiciones del contrato de transporte, e impone y cobra la tarifa. Todas estas actividades son propias de una empresa que ofrece un servicio de transporte.

El servicio de taxi tiene por objeto el traslado del pasajero a cambio del pago de una tarifa. Como ya se mencionó, es con Uber con quien se contrata el servicio de transporte, y es con Uber con quien se pactan y se acuerdan todos los aspectos relevantes del contrato. Esto se acredita respondiendo a las preguntas que aparecen a continuación.

\section{¿A quién solicita el usuario el servicio de transporte?}

Lo solicita a Uber, a través de la aplicación creada por ellos y puesta a disposición por ellos en el mercado.

El usuario también informa a Uber cuál es el lugar de recojo y cuál es el lugar de destino. Contrariamente a lo que sostiene la empresa, el usuario no solicita al conductor el servicio, tampoco le informa cuál es el lugar donde debe recogerlo ni el destino al que debe llevarlo. Esa información es trasladada por el usuario únicamente a Uber.

\section{¿Quién determina la tarifa que se pagará por el servicio?}

Uber lo hace. Una vez fijado el punto de inicio y el punto de destino, Uber señala la tarifa que se cobrará por el servicio.

No existe negociación alguna entre usuario y chofer. Una vez solicitado el servicio e informada la tarifa, no existe libertad alguna entre el conductor y el pasajero para negociar la tarifa que se cobrará por el servicio prestado. Uber la impone y la informa al pasajero antes que este 
tenga algún contacto con el chofer; de hecho, el pasajero ni siquiera conoce la identidad del mismo.

¿Quién determina el chofer y la unidad que recogerá al usuario?

Nuevamente, Uber lo hace.

En un primer momento, afilia únicamente a los supuestos taxistas que cumplen con los requisitos por ellos impuestos. Luego el usuario no tiene posibilidad alguna de escoger con cuál unidad o taxista, entre los que Uber ha permitido afiliarse, quiere "contratar". Es Uber quien de manera unilateral designa la unidad y el chofer que brindará el servicio de transporte al pasajero.

Es más, el usuario nunca llega a conocer la identidad del taxista que lo transporta. Uber únicamente informa al consumidor el nombre de pila del taxista y viceversa, pues el taxista tampoco conoce la identidad del pasajero.

\section{¿Quién cobra por el servicio brindado?}

Uber es quien realiza el cobro, no el chofer.

El usuario no le paga al taxista por el servicio brindado, sino que la tarifa es cobrada directamente por Uber a través de una tarjeta de crédito. Si bien en algunos casos los pagos se hacen en efectivo, en esos supuestos los choferes deben reintegrar a la empresa el pago de la comisión que a ellos les corresponde.

En estas condiciones, ¿es válido afirmar, como Uber lo hace, que solo es una plataforma que pone en contacto a usuarios con choferes? Evidentemente, no. No interesa cómo es que Uber llame al servicio que brinda; si lo llama "plataforma de intermediación" o "servicio de conductor privado", es irrelevante. De aplicar la ordenanza que regula el servicio de taxi en Lima, Uber calza a la perfección con su supuesto de hecho; ergo, Uber brinda un claro servicio de taxi.

A la misma conclusión llegamos si aplicamos el principio de primacía de la realidad, acorde con el artículo 5 de la Ley de Represión de la Competencia Desleal (Decreto Legislativo 1044, 2008) que señala:

La autoridad administrativa determinará la verdadera naturaleza de las conductas investigadas, atendiendo a las situaciones y relaciones económicas que se pretendan, desarrollen o establezcan en la realidad. 
La forma de los actos jurídicos utilizados por los contratantes no enerva el análisis que la autoridad efectúe sobre la verdadera naturaleza de las conductas subyacentes a dichos actos.

Independientemente del nombre que Uber le ponga al servicio que brinda, si los llama taxistas o usuarios conductores, o si informó previamente que ellos no brindan un servicio de transporte, de la realidad se desprende que la verdadera naturaleza de la actuación de Uber es prestar un servicio de taxi.

¿En qué se diferenciaría el servicio de "conductor privado" o "plataforma tecnológica" de Uber con la prestación de un servicio de taxi de una empresa formalmente constituida? Al parecer, en nada. Ambas empresas brindan exactamente el mismo servicio (transportan pasajeros de un lugar a otro según es indicado por el cliente), ambas lo hacen mediante un taxista y un auto asignados por la compañía, y a cambio del pago de una tarifa determinada por dicha empresa.

Solo existe una diferencia, en nuestra opinión, radical: Uber no cumple con la ley que sí obedecen todos los demás taxistas que operan de conformidad con lo establecido en la Ordenanza Municipal 1684 (2013). Mientras todos los demás sí lo hacen, Uber no cumple ni siquiera con tener una licencia.

Una cuestión análoga se puede plantear respecto al ámbito laboral: ¿son o no "trabajadores" los conductores de Uber? En varias partes del mundo, ya se han expuesto este tipo de demandas ("Uber gana caso sobre situación laboral de conductores en Francia", 2017). De considerarse trabajadores, Uber no estaría pagando derechos laborales, en clara ventaja sobre todas las demás empresas que sí tienen contratos laborales "formales" con sus conductores.

Situación parecida ocurre con los impuestos. En cada transacción, Uber realiza los cobros a través de la tarjeta de crédito en Países Bajos (no en el Perú), mediante la persona jurídica Uber B. V. Una vez recibido el dinero $-\mathrm{y}$ luego de haber restado lo que corresponde a los conductores y gastos operativos-, esta empresa debería pagar impuestos sobre el monto restante (en Países Bajos, al menos). ¿Lo hace? La respuesta corta podría ser que no. Según respetables opiniones extranjeras, lo que hace Uber B. V. es transferir ese monto a Uber International CV (también constituida en Países Bajos), en calidad de "regalías por propiedad intelectual", aprovechando que, en Países Bajos, las leyes 
exoneran de impuestos a este tipo de regalías ("El otro lado de Uber: de la estrategia para pagar menos impuestos a los problemas con los conductores", 2016).

Si Uber no paga impuestos en el Perú por los beneficios que obtiene de rentas que son evidentemente de fuente peruana, ¿qué puede hacer el Estado peruano (en el aspecto tributario) para evitarlo? Pues lo "lógico" sería buscar alguna interpretación en la normativa que haga que Uber deba pagar impuestos en el país. ¿Y en el ámbito laboral? Si se cumple con todos los requisitos de la relación laboral, hay que demandar a Uber que pague todos los beneficios laborales correspondientes. ¿Y en lo administrativo? Exigirle permisos, registros y licencias que Uber está lejos de cumplir.

Finalmente, si nada de esto es hecho por las empresas tradicionales de taxi, mucho menos por los taxistas independientes, entonces, a la luz de la normativa actual, es claro que Uber tiene ventaja sobre ellos, compite deslealmente.

\section{Más MerCado, MENOS NORMAS}

¿Uber y los demás taxis por aplicación compiten deslealmente en el mercado? La respuesta es obvia: a la luz de la normativa actual, por supuesto que sí. ¿Debemos, entonces, eliminar a Uber y los demás aplicativos? Para nosotros, la respuesta también es obvia: por supuesto que no. La mayoría de los lectores seguramente coincidirán con nosotros, dado que, más allá de algunos problemas con pasajeros que se han presentado, el servicio de taxi por aplicaciones es útil y beneficioso (de lo contrario, nadie lo usaría).

¿Por qué los creadores de estas aplicaciones decidieron crearlas? Porque encontraron un "vacío" aprovechable en el mercado. El problema, empero, fue legal: como ocurre siempre con todas las ideas novedosas, ninguna ley las regula, pues no existían al momento de la creación de dicha ley. Mientras el mercado, por su naturaleza, es siempre dinámico (siempre cambia), la legislación, por su parte, es siempre estática (ninguna ley cambia espontáneamente).

La regulación no siempre es la mejor manera de proteger los intereses de la sociedad: por regularlo todo, terminamos frustrando cualquier innovación. Movidos por una ingenua, pero perniciosa obsesión de regular y llenar de requisitos todo lo que conocemos para 
protegernos de lo que desconocemos, no nos damos cuenta de que nos perjudicamos incluso a nosotros mismos. Así ocurre con los aplicativos de taxis, empresas que, de exigirles la normativa actual de libre competencia, laboral y fiscal, no podrían continuar operando.

Por eso, consideramos que si queremos, como sociedad, favorecer la innovación, lo que debemos hacer es eliminar las normas excesivamente restrictivas (y así impulsar a que los empresarios se sigan concentrando en lo que realmente importa: mejorar sus servicios) o, en su defecto, reformar las ya existentes. Abstraerlas lo suficiente para que todas las nuevas ideas, incluyendo tanto las que ahora existan como las futuras que no podemos prever, puedan participar y competir legalmente dentro del mercado. No necesitamos una nueva ley que regule las aplicaciones de transporte ${ }^{5}$. No. Eso implicaría seguir cayendo en la nociva trampa lógica de la legislación. Lo que necesitamos, en todo caso, es reformar la ordenanza municipal vigente por una norma lo suficientemente general y abstracta que permita a todos los operadores que brindan el servicio de taxi, tanto a los independientes como a las empresas y aplicativos, competir libremente. De lo contrario, estas aplicaciones, o seguirán viéndose forzadas a escudarse en términos y condiciones retóricos con el único fin de negar la naturaleza del servicio que prestan y tratar de evadir su responsabilidad frente a los usuarios, o, peor aún, se prohibirán indefinidamente en el país, pues bajo la normativa actual todas incurren en competencia desleal.

\section{REFERENCIAS}

Decreto Legislativo 1044, Ley de Represión de la Competencia Desleal. (26 de junio del 2008). Recuperado del sitio de internet de Indecopi: https://www.indecopi.gob.pe/documents/20182/143803/ leyrepresioncompetennciadesleal.pdf

El otro lado de Uber: de la estrategia para pagar menos impuestos a los problemas con los conductores. (14 de abril del 2016). La Nación. Recuperado de http://www.lanacion.com.ar/1889293-el-otrolado-de-uber-la-estrategia-para-pagar-menos-impuestos-y-losproblemas-de-seguridad

5 El 8 de junio del 2017 se publicó el proyecto de ley que crea y regula el servicio privado de transporte a través de plataformas tecnológicas. 
Ordenanza Municipal 1684, Ordenanza que regula la prestación del Servicio de Taxi en Lima Metropolitana. (14 de abril del 2013). Recuperado del sitio de internet del Servicio de Administración Tributaria de Lima: https://www.sat.gob.pe/Websitev8/Modulos/ documentos/normas/papeletas/Ordenanza1684.pdf

Taleb, N. (2008). El cisne negro. El impacto de lo altamente improbable (1. ${ }^{\mathrm{a}}$ ed.). Barcelona: Paidós.

Uber B. V. (29 de julio del 2015). Pero al fin de cuentas, ¿qué es Uber y cómo se usa? [mensaje en un blog]. Recuperado de https://www. uber.com/es-CL/blog/que-es-uber/

Uber gana caso sobre situación laboral de conductores en Francia. (16 de marzo del 2017). Gestión. Recuperado de https:/gestion.pe/ economia/empresas/uber-gana-caso-situacion-laboralconductores-francia-130806

Uber es prohibido en Italia por competencia desleal. (9 de abril del 2017). El Comercio. Recuperado de https://elcomercio.pe/ tecnologia/actualidad/uber-prohibido-italia-competenciadesleal-421272

Uber B. V. (13 de diciembre del 2017). Términos y condiciones. Recuperado de https://www.uber.com/es-PE/legal/terms/pe/ 
